http://jmscr.igmpublication.org/home/

ISSN (e)-2347-176x ISSN (p) 2455-0450

crossref DOI: https://dx.doi.org/10.18535/jmscr/v9i5.34

Journal Of Medical Science And Clinical Research

IGM Publication

An Official Publication of IGM Publication

\title{
Pupilloplasty with Intraocular Lens Implantation in Repaired Corneal Tear with Incarcerated Iris and Traumatic Cataract: A Case Report
}

\author{
Authors \\ Dr Sarika Dubey ${ }^{1}$, Dr Pankaj Sharma ${ }^{2}$, Dr Apoorva Priyadarshani ${ }^{3 *}$, \\ Dr Nikita Jain ${ }^{4}$, Dr Kulveer Singh ${ }^{5}$ \\ ${ }^{1}$ Assistant Professor, Department of Ophthalmology, SMS Medical College and Hospital, Jaipur \\ ${ }^{2}$ Professor, Department of Ophthalmology, SMS Medical College and Hospital, Jaipur \\ 3,4,53 year Resident, Department of Ophthalmology, SMS Medical College and Hospital, Jaipur \\ *Corresponding Author \\ Dr Apoorva Priyadarshani
}

\begin{abstract}
We present a case of a 4 year old female with repaired corneal tear 3 months back due to penetrating ocular trauma by an unknown object. She complained of sudden diminution of vision. On examination, traumatic cataract with iris incarceration in wound and posterior synechiae were observed which was managed successfully by pupilloplasty followed by traumatic cataract extraction with anterior vitrectomy and sulcus intraocular lens (IOL) implantation.

Post surgery the BCVA improved from FCCF to 5/60 on first post-operative day with a round and regular pupil.

Keywords: Penetrating ocular trauma, Traumatic cataract, Pupilloplasty, Sulcus IOL.
\end{abstract}

\section{Introduction}

Ocular trauma is a common cause of vision loss in the developing world, especially in the school-age pediatric population and is a major etiology for unilateral cataract formation in a normal-sized eye. ${ }^{[1]}$ It has been reported that ocular trauma occurs in 3.45 per 100000 population per year or 4.6 per 10000 outpatient visits. ${ }^{[2]}$ Traumatic cataract is encountered in $27-65 \%$ of the ocular trauma cases. ${ }^{[3],[4],[5]}$ Traumatic cataract surgery is performed either as an early procedure in association with the repair of laceration in open globe injury, at early days after presentation of penetrating injury or as a late procedure in a quiet eye. We report a case of a complicated traumatic cataract managed by pupilloplasty, traumatic cataract extraction and sulcus IOL implantation 3 months after primary repair with very good postoperative visual outcome.

\section{Case Report}

A 4- year- old female is a follow up case of left eye repaired corneal tear 3 months back after sustaining penetrating ocular trauma by an unknown object. Now, presented with complaints of sudden diminution of vision in her left eye.

At presentation, the uncorrected visual acuity (UCVA) in her left eye was PL+PR accurate HM FCCF. 
Cornea had four interrupted 10.0 nylon sutures from previous surgery. Anterior chamber (AC) was shallow with cortical lens matter in AC. Posterior synechiae were present with cortical lens matter and iris adherent to the internal part of wound. There was a dense fibrotic membrane in the pupillary axis, which was probably a partially absorbed cataract. Pupil was irregular and non reactive (Fig 1).Axial length of left eye calculated by A-scan was $22.5 \mathrm{~mm}$. K1 (44.94) and K2 (45.92) of right eye was used using automated keratometer. The IOL power of left eye as calculated by IOL Master was 21.5D using SRK II formula. B Scan ultrasonography of left eye showed traumatic cataract with anechoic posterior segment. Examination of the right eye was within normal limits and the unaided visual acuity was 20/20.

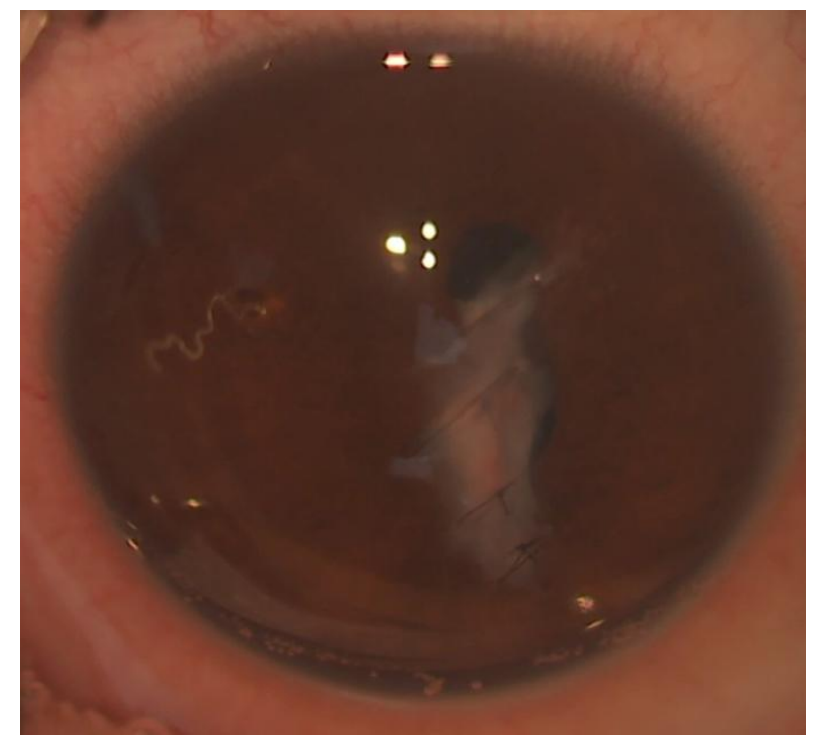

Fig 1: Preop picture showing corneal sutures from previous surgery with incarcerated iris and irregular pupil.

We advised the patient's parents for traumatic cataract extraction with/without pupilloplasty with/without IOL implantation under general anaesthesia after proper explanation of risks and a poor visual prognosis in view of the large paracentral corneal scar.

\section{Procedure}

Under general anaesthesia, and proper draping, the four corneal 10.0 nylon interrupted sutures were removed (Fig 2). A side port was made at 5'0 clock position.1.4\% sodium hyaluronate was injected to form the AC. The $2.2 \mathrm{~mm}$ main port was made supero-temporally, centered at 2 o'clock. Vannas scissors was used to release the iris incarcerated in the posterior lip of the repaired corneal tear (Fig 3). Another $2.2 \mathrm{~mm}$ port was made at 12 o'clock. A small opening was made in the fibrotic membrane with a $26 \mathrm{G}$ needle and the membranous cataract was cut with Vannas scissors (Fig 4). A sphincterotomy at 11 o'clock was done and pupilloplasty was completed through the 12 o'clock port (Fig 5-7).Limited partial anterior vitrectomy was done through the main port to clear the debris and blood in the pupillary axis. Residual lens matter was aspirated by the IAC mode of the vitrector. Posterior synechiae were noted between the residual lens capsule and iris. Viscodissection was done to separate and create space between the iris and the membrane. Blunt and gentle dissection with Sinskey's hook was done to separate the posteriorsynechiae. Thus space was created for implantation of IOL. A hydrophilic acrylic foldable IOL was injected in the ciliary sulcus (Fig 8). Residual ocular viscoelastic device (OVD) and lens matter was aspirated. Air was injected and the ports were closed with 10.0 monofilament nylon sutures (Fig 9). Subconjunctival gentamicin-dexamethasone was injected. Atropine ointment was applied before applying pad and patching the eye. Systemic steroids were started in the dose of $1.5 \mathrm{mg} / \mathrm{kg}$ body weight apart from systemic antibiotics. 


\section{JMSCR Vol||09||Issue ||05||Page 186-190||May}

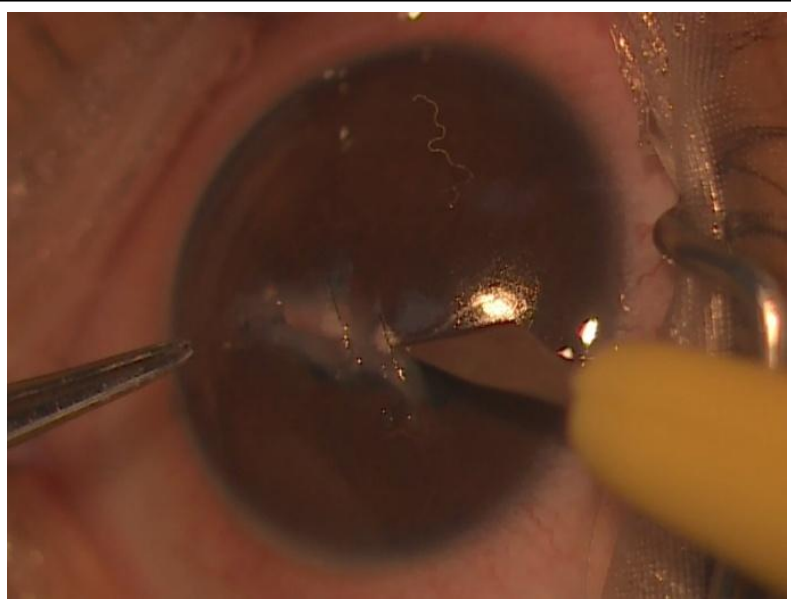

Fig 2: Removal of pre existing corneal sutures

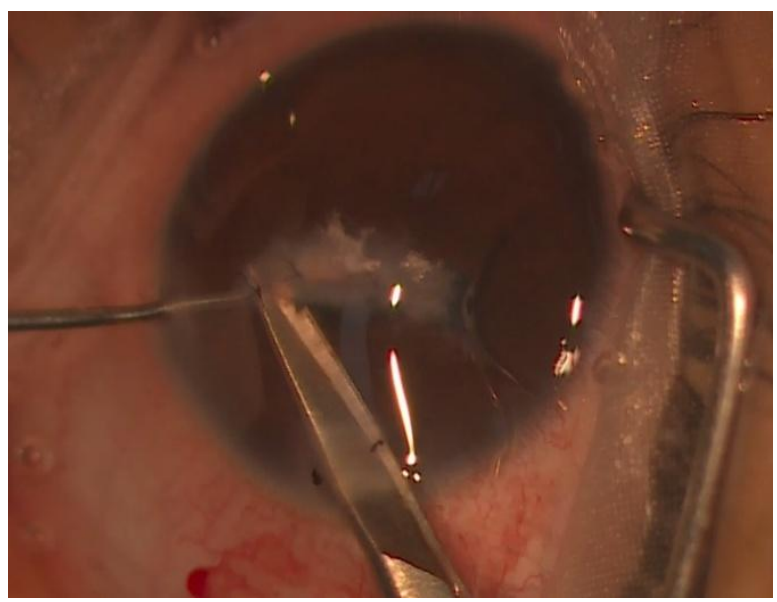

Fig 3: Releasing incarcerated iris from wound

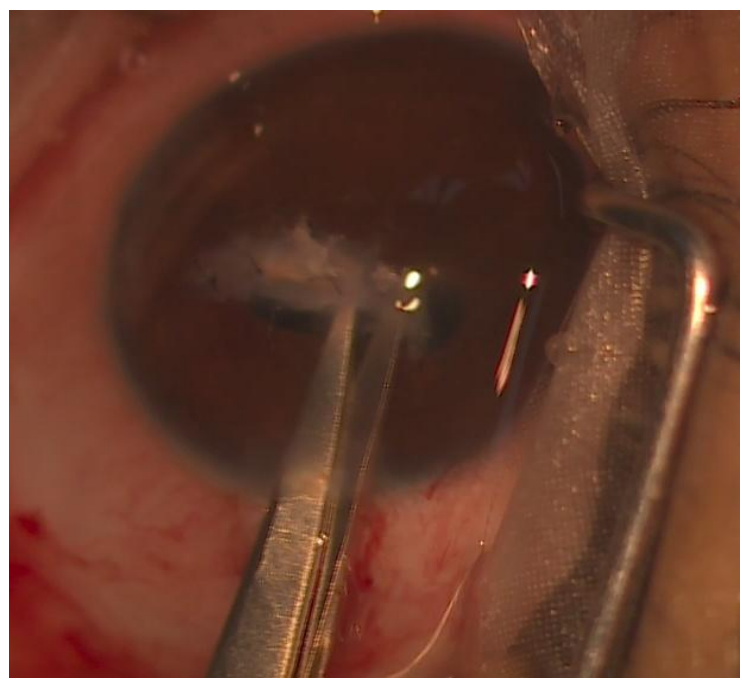

Fig 4: Cutting of membranous cataract
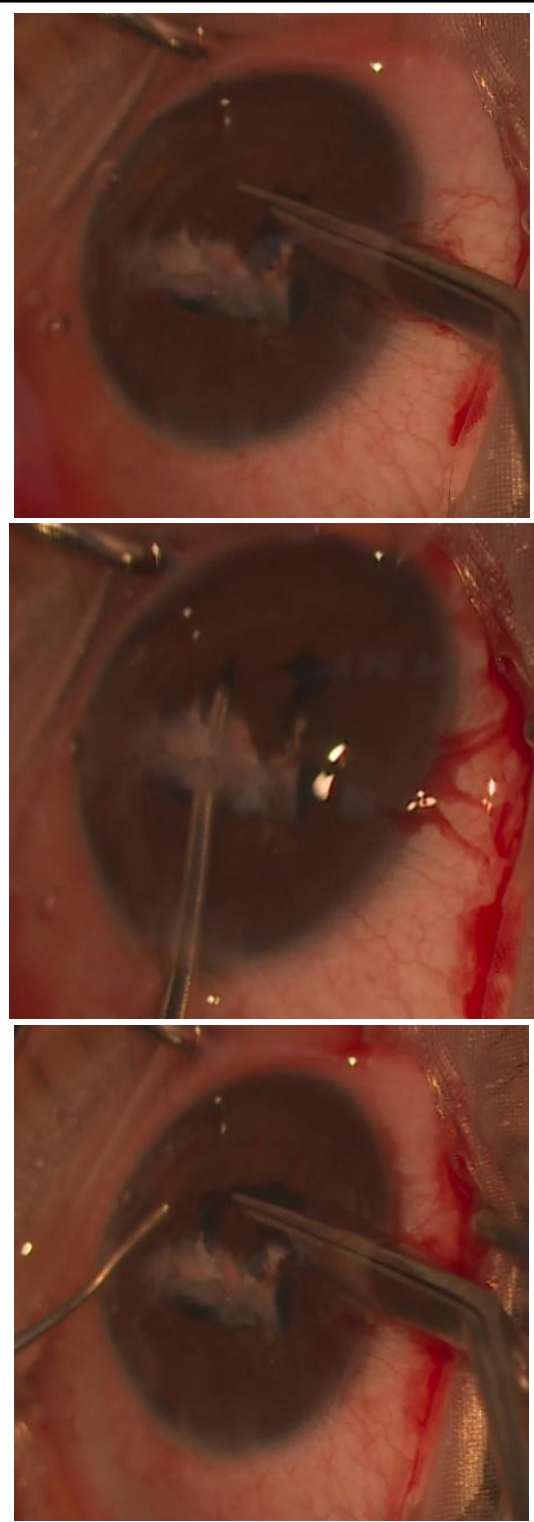

Fig 5 - 7: Pupilloplasty by sphincterotomy

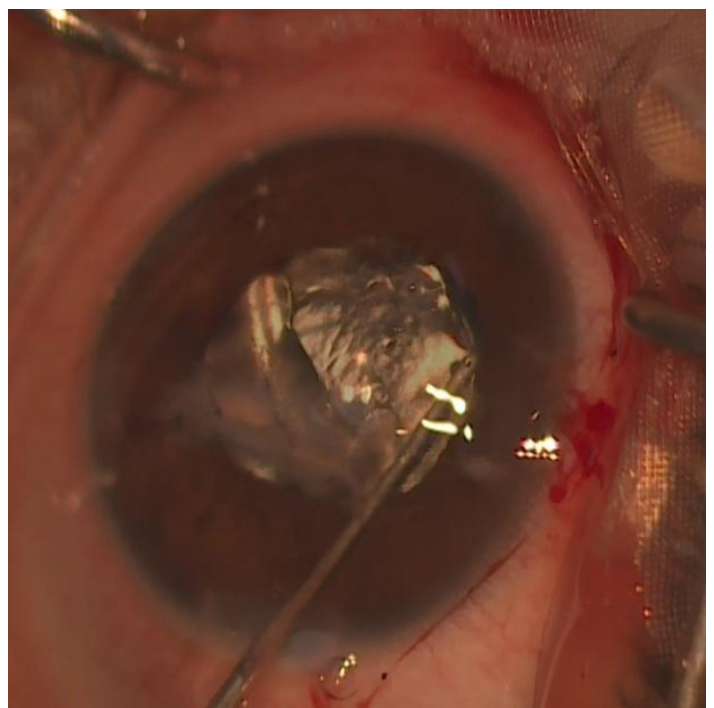

Fig 8: IOL implanted in sulcus 


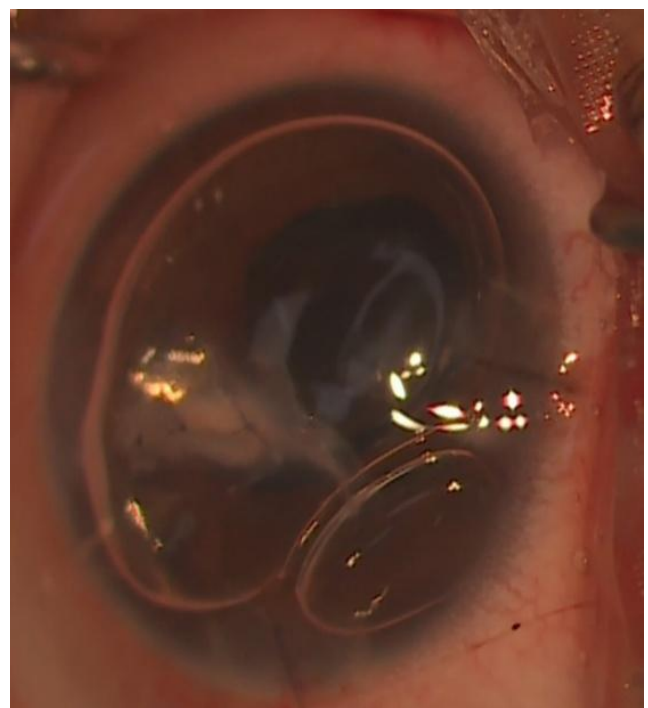

Fig 9: AC formed with air bubble and ports sutured

Day 1 post-op patient had 5/60 vision unaided. The eye had minimal AC reaction and well- secured wound with IOL in place on postoperative day 1(Fig 10) and day 3. Vision improved to $6 / 36$ on day three post-op. Pupil in left eye was round, regular and dilated under drug.

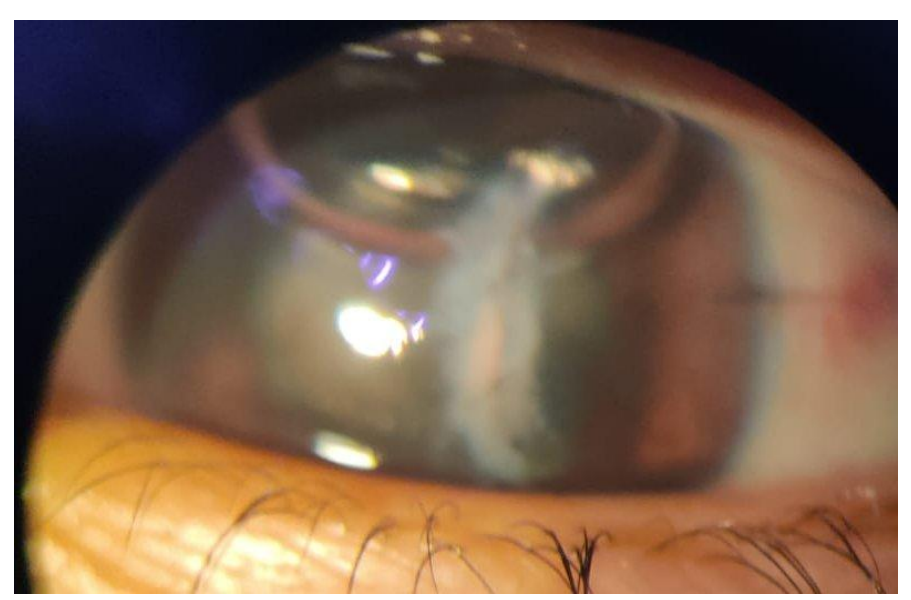

Fig 10: Post - op Day 1- AC formed with IOL in place. (Patient was non cooperative for examination owing to the blurred image)

The patient remained comfortable throughout the postoperative period. There were no intraoperative and postoperative surgical complications. Postoperatively, Moxifloxacin $0.5 \%+$ Prednisolone $1 \%$ e/d 1 hourly, CMC $0.5 \%$ e/d 2 hourly, Atropine 1\% e/d TDS, Timolol $0.5 \%+$ Brimonidine $0.2 \%$ e/d BD, Tab Acetazolamide 125mg BD, Tab Diclofenac+Paracetamol BD, Tab
Prednisolone 20mg ODPC and Tab Lansoprazole $15 \mathrm{mg}$ ODAC was given.

\section{Discussion}

Ocular trauma is a common cause of vision loss in the developing world, especially in the school-age pediatric population, and is a major etiology for unilateral cataract formation. ${ }^{[1]}$ Paediatric traumatic cataracts are often accompanied by increased inflammation; amblyopia; injury to the cornea, uveal tissue, and angle structures; anterior and/or posterior lens capsule rupture; lens dislocation; and posterior segment complications. Shah et $\mathrm{al}^{[6]}$ concluded that it is better to perform the traumatic cataract surgery as an early procedure because of lower complication rate as well as sooner and better visual rehabilitation.

Agarwal et $\mathrm{al}^{[7]}$ have suggested that in the presence of severe corneal damage and edema it is better to postpone lensectomy for better visualization during surgery. Trauma associated with rupture of anterior capsule and presence of lens material in AC, may lead to IOP rise and prolonged inflammation, which may cause anterior and posterior synechiae. The longer existence of synechiae the more difficult the surgery will be. Therefore, the repair of the traumatic wound and lensectomy is better to be done at the same session. ${ }^{[8]}$

In our case, the patient had her primary corneal repair done 3 months back. Traumatic cataract was not managed immediately to allow for subsiding of corneal edema and inflammation. During surgery, the incarcerated iris was released which could be due to increased inflammation post operatively. An anterior capsule tear was present, therefore capuslorrhexis was not done. The cataract was soft and membranous and the lens matter was leaking into the $\mathrm{AC}$ which was probably responsible for the various inflammatory reaction causing complications. Hydro dissection was not done as vitreous was found in the anterior chamber due to a posterior capsule break, so anterior vitrectomy was done to prevent scaffolding. Repeated viscoelastic injections were 
performed in the anterior chamber during the procedure in order to maintain its stability and protect the corneal endothelium. Posterior synechiae were released gently so as to avoid hampering the possible space in sulcus. In our case, fortunately capsular support was present and an intact sulcus could be formed which aided in the implantation of a hydrophilic IOL in the sulcus.

\section{Conclusion}

Timely intervention with appropriate IOL implantation in post traumatic cataract can lead to excellent visual and anatomical outcome.

\section{Declaration of Patient Consent}

The authors certify that they have obtained all appropriate patient consent forms. In the form the patient (s) has/have given his/her/their consent for his/her/their images and other clinical information to be reported in the journal. The patients understand that their names and initials will not be published and due efforts will be made to conceal their identity, but anonymity cannot be guaranteed.

Financial support and sponsorship: Nil.

Conflicts of interest: There are no conflicts of interest.

\section{References}

1. Shah MA, Agrawal R, Teoh $\mathrm{R}$, et al. Pediatric ocular trauma score as a prognostic tool in the management of pediatric traumatic cataracts. Graefes Arch Clin Exp Ophthalmol 2017; 255 (5): 102736.

2. Rumelt S, Rehany U. The influence of surgery and intraocular lens implantation timing on visual outcome in traumatic cataract. Graefes Arch Clin Exp Ophthalmol 2010; 248(9): 1293-1297.
3. Dannenberg AL, Parver LM, Brechner RJ, Khoo L. Penetration eye injuries in the workplace. The National Eye Trauma System Registry. Arch Ophthalmol 1992; 110(6): 843-848.

4. Slusher MM, Greven CM, Yu DD. Posterior chamber intraocular lens implantation combined with lensectomyvitrectomy and intraretinal foreign-body removal. Arch Ophthalmol 1992; 110(1): 127-129.

5. Pieramici DJ, Sternberg Jr P, Aaberg Sr TM, Bridges Jr WZ, Capone Jr A, Cardillo JA et al. A system for classifying mechanical injuries of the eye (globe). The Ocular Trauma Classification Group. Am J Ophthalmol 1997; 123(6): 820-831.

6. Shah MA, Shah SM, Shah SB, Patel UA. Effect of interval between time of injury and timing of intervention on final visual outcome in cases of traumatic cataract. Eur J Ophthalmol 2011; 21(6): 760-765.

7. Agarwal A, Ashok Kumar D. How to manage the complications of a traumatic cataract, ocular surgery news U.S. Edition. Available at: http://www.healio.com/ophthalmology/cat aract-surgery/news/print/ocular-surgerynews/\%7Ba5742be5-6e8a-43c8-a2411598aac8449a\%7D/how-tomanage-thecomplications-of-a-traumatic-cataract.

8. Agrawal R, Keane PA, Singh J, Saihan Z, Kontos A, Pavesio CE. Classification of semi-automated flare readings using the Kowa FM 700 laser cell flare meter in patients with uveitis. Acta Ophthalmol 2016; 94(2): e135-e141. 